\title{
Banana as a Cash Crop and Its Food Security and Socioeconomic Contribution: The Case of Southern Ethiopia, Arba Minch
}

\author{
Molla Mekonnen Alemu \\ University of Leicester, Leicester, UK \\ Email: mollamekonnen@gmail.com
}

How to cite this paper: Alemu, M.M. (2017) Banana as a Cash Crop and Its Food Security and Socioeconomic Contribution: The Case of Southern Ethiopia, Arba Minch. Journal of Environmental Protection, 8, 319-329.

https://doi.org/10.4236/jep.2017.83024

Received: February 4, 2017

Accepted: March 24, 2017

Published: March 27, 2017

Copyright $\odot 2017$ by author and Scientific Research Publishing Inc. This work is licensed under the Creative Commons Attribution International License (CC BY 4.0).

http://creativecommons.org/licenses/by/4.0/ (c) †) Open Access

\begin{abstract}
Food security is a challenge in many developing countries. Nations are still struggling to make use of available resources so as to combat hunger. Drought, land degradation, marketing constraints, improper post-harvest handling and anthropogenic factors are minimizing the production and productivity of agricultural land resources. Making use of improved technologies, adaptable crops and high yielding cash crops, however, are also helping many to cope up with food insecurity. Banana production is significantly contributing for food security as well as livelihood opportunities in Southern Ethiopia. But, technical works on the value chain of the crop are still minimal; it would have resulted a tangible impact on the national income in terms of export earnings and food security too. The Southern Ethiopia, Gamo Gofa Zone is the leading banana producer in the country. This article assesses the potential contribution of banana production to food and income security in the area. The paper also explored the major banana production maximization bottlenecks. 63 farmers of Arba Minch Zuriya District were interviewed to extract primary information. Discussions were held with Government officials. Different reports and related literatures were also reviewed. The result showed that, banana production was having a significant role for the wellbeing of the community explained in terms of food security, income source and serving as source of feed for livestock. Problems associated with marketing and post-harvest handling are also identified being production problems. The fact that, the production of banana is mainly dominated by men has also let the men to sell the crop and have an independent control over the cash. Therefore, community awareness development, improving production systems and developing the culture of saving could help to have a sustained impact of banana production in the region.
\end{abstract}

\section{Keywords}

Banana, Cash Crop, Food Security 


\section{Introduction}

The present day, dessert banana history is entrenched in South East Asia. The Spanish and Portuguese are also recognized for introducing it to the Americas in the $16^{\text {th }}$ century. It is also believed as bananas are introduced to the African continent in the prehistoric era [1].

Banana is a major fruit crop grown in many developed and developing countries. The production distribution mainly lies in between $30^{\circ}$ North and South latitudes at about $60^{\circ} \mathrm{F}$ or above winter temperatures and $100 \mathrm{~mm}$ of average monthly rainfall distribution. Banana can also grow in frost free cold areas [2].

Globally, banana is the fourth most important crop of the food market next to rice, wheat and maize. This makes banana to be the prime leading fruit crop in terms of volume and value in the world market [3].

As indicated in Figure 1, bananas are known for their high nutritional values too. Potassium, fiber, magnesium, and vitamin C and B6 are among the nutritious contents in it. It is also believed as bananas help to fight depression, kidney cancer and diabetes [4].

In 2013, the global banana export exceeded 17 million-tonnes, 6.5 percent increase as compared with the year 2012 export rate, Latin America and the Caribbean being the leading suppliers to the world market. Ecuador is the leading producer in the Latin and Dominican being the largest in the Caribbean. For Asian

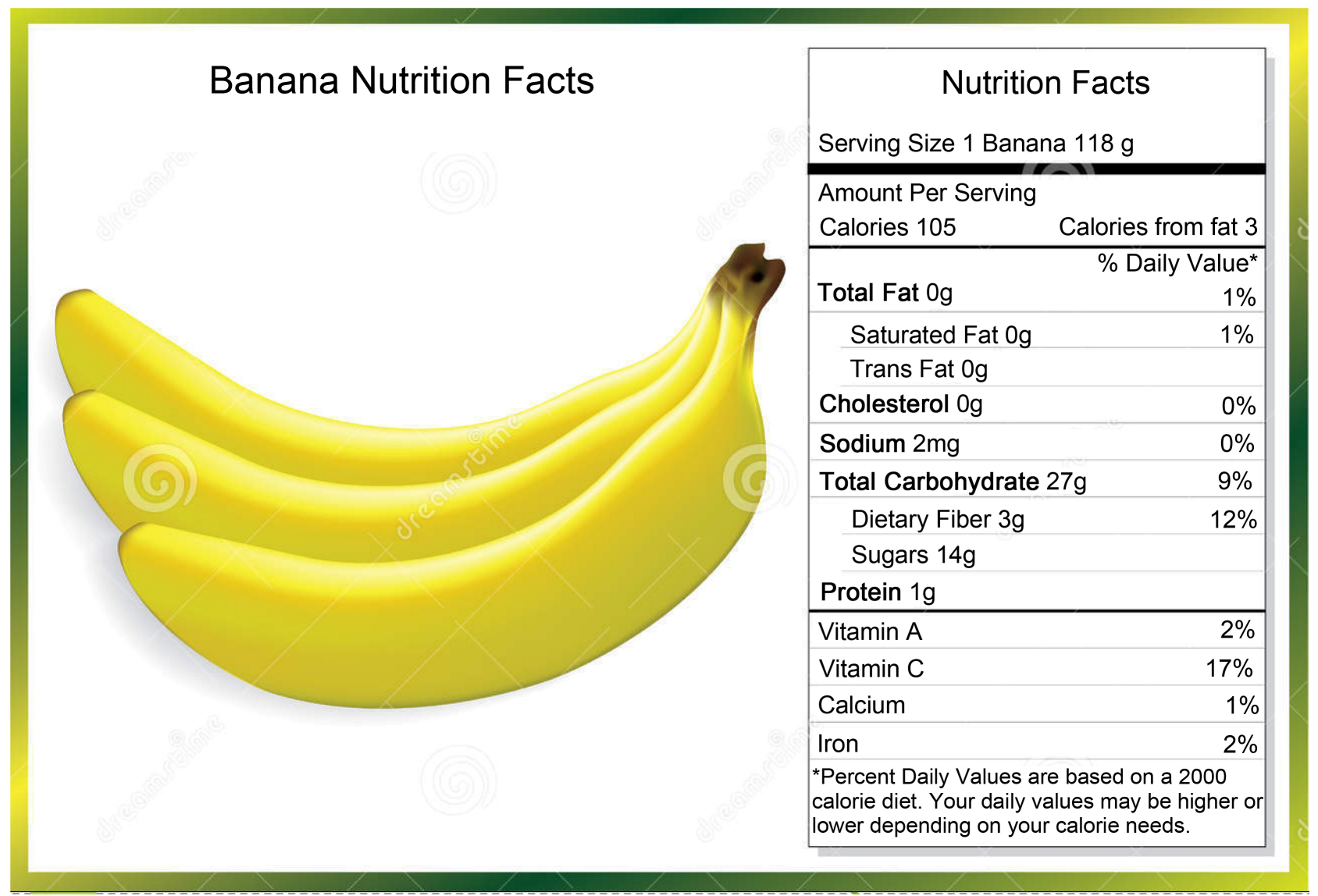

Figure 1. Nutrition values of Bananas [5]. 
exporters, mainly the Philippines (the leading exporter in the region and the second largest supplier globally) has also supplied 2.7 million.tonnes of banana to the market in 2013 (Figure 2). In 2013, Africa had also showed a magnificent banana production growth rate of $5.6 \%$ by exporting 665,000 tonnes with a major contribution from Côte d'Ivoire (the leading exporter in the region) and Cameroon (the second largest exporter in Africa). As depicted in Figure 3, the European Union, United States and the Russian Federation are the leading importers of banana in the world [6]. In the year 2010, the total banana world commerce valued at $\$ 8.05$ billion [3].

The production of banana, however, is being challenged by several agronomic and market related factors. Banana plant diseases such as Race4 (TR4) also known as the Panama are posing a severe threat to the Cavendish variety of the crop, the largest banana variety world-wide. This effect is exacerbated by the monoculture production system and trends of banana plantations. For the fact that, bananas are grown on big plantations, the production is known to favor increased and fast infestation of the environment by pests. The increased dependency of

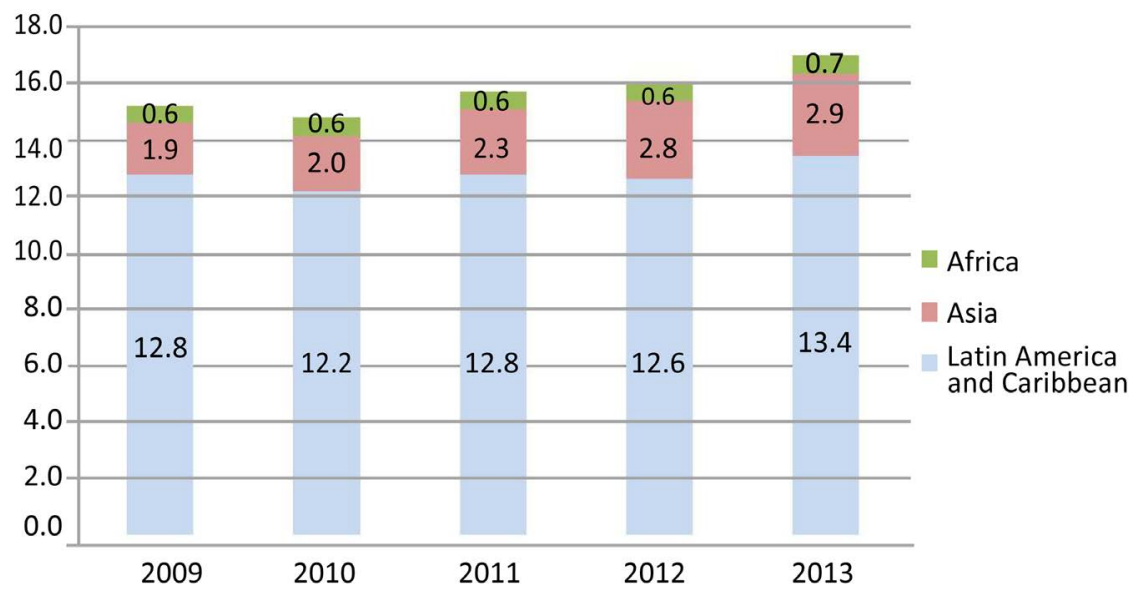

Figure 2. Banana exports by region 2009-2013, million.tones [6].

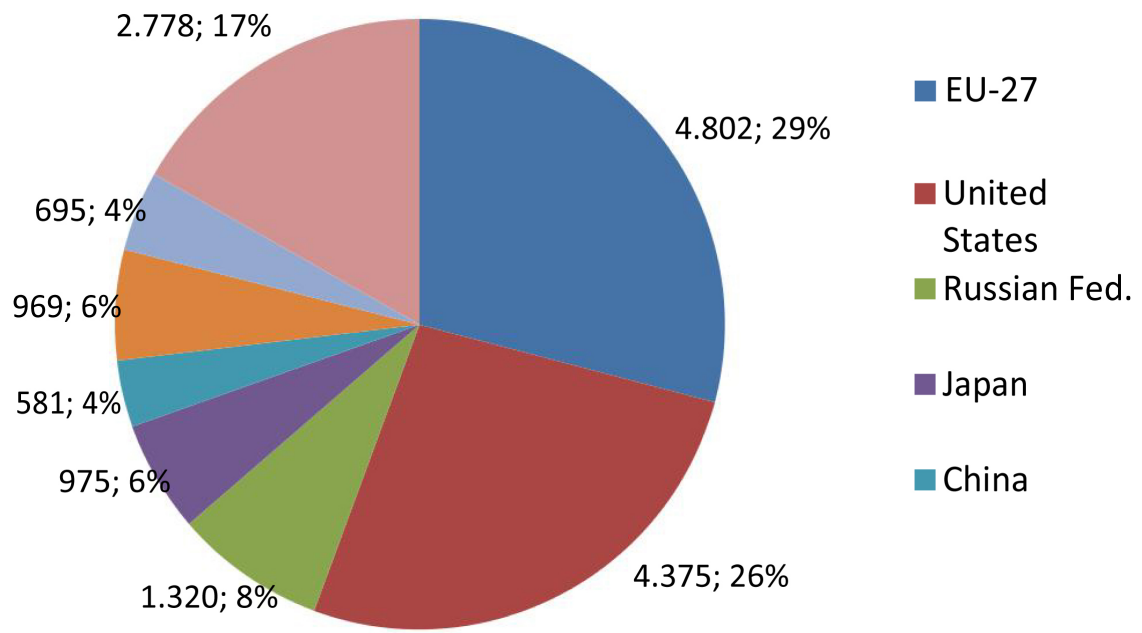

Figure 3. Distribution of global imports by market, 2013 (thousand tonnes and share in global imports) [6]. 
agricultural chemicals has also contributed to environmental pollution coupled by increased health related risks for the workers. This study is, therefore, held in one of the leading banana producing areas of Ethiopia so as to assess the potential contributions of banana production to food and income security in Arba Minch district area and also explore the major banana production maximization bottlenecks which could inform policy and decision makers in ameliorating the challenges of banana production in the area.

\section{Banana Production in Ethiopia}

In Ethiopia, the modern banana production was started at the beginning of this century with the establishment of the state farms and different plantations such as large scale sugarcane plantations. The production system of the crop is mainly composed of 1) small plantations in home gardens owned by small farmers-especially in the South-Western and Western provinces; 2) medium-sized plantations of not more than 10 ha supplying local consumers; and 3) relatively large plantations above 20 ha developed to supply export markets [2].

The export business of banana in Ethiopia dates back to 1961 where the country started at about 5000 tonnes. This figure, however, increased to 60,000 tonnes by the year 1972 when the country exported to different countries of Europe, Asia and Africa. In 1975 the total production of banana in the country has reached about 100,000 tonnes [2] [7].

In Ethiopia, in terms of consumption and production, among the horticultural crops of the country the dessert banana is the leading fruit crop. At present it is believed to cover about $86 \%$ (478,251.04 tones) of the total fruit production. The crop grows in various parts of the country in the form of home garden crop at a household level to large scale plantations. The Southern Nations and Nationalities Peoples' Regional State of the country is the leading banana producer region which accounts for $68.72 \%$ (37,076.85 hectares) area of land coverage by banana production, $77.53 \%$ (370,784.17 tones) of the fresh banana produce and $22.38 \%(1,504,207)$ of the banana producers. This has favored the region to benefit from increased food security, income generation, employment opportunities and from the enhancement of local and regional economic developments [3] [8] [9].

From the Southern region, GamoGofa, Bench Maji and Sheka are the leading zones of the total banana production; GamoGofa zone taking about $70 \%$ of the total banana market supply of the country [9].

According to Fanos [10], banana production in the Arba Minch Zuriya district of Gamo Gofa zone dates back to the early 1980s, where the then Arba Minch State Farm had about 62 hectares of land covered by the Dwarf Cavendish banana variety. During that time the crop lands of the smallholder farmers were occupied by maize, cotton and sweet potato. Then, there were frequent trials which were held to introduce the crop to the nearby Lante area, even though that effort was not successful at that time since banana was not perceived as an important cash as well as nutritional crop. In 1984, however, the effort was able to cover the 4.2 
hectares of the then Lante Cooperatives land by the Cavendish banana variety and later it was expanded to individuals land and the surrounding districts. The Arba Minch banana, as a result of its taste, is the most preferred variety of banana in the country and has the highest demand throughout the markets of the country at present. Irrigated banana production (Dwarf, Medium height and Giant Cavendish) presently covers about 11,000 ha of land in Arba Minch Zuria and Mirab Abaya districts.

\section{Methodology}

\subsection{Description of the Study Area}

GamoGofa zone is located in the Southern Nations and Nationalities Peoples' Regional State of the Federal Democratic Republic of Ethiopia. Arba Minch Zuriya is one of the districts of GamoGofa zone and serves as the seat of the zonal administration. The district is located about $505 \mathrm{~km}$ south west of Addis Ababa and has a total of 29 Kebeles (the smallest administration unit in the country)

(Figure 4). Agro ecologically 4 Kebeles are highlands, 15 Kebeles at mid-altitude

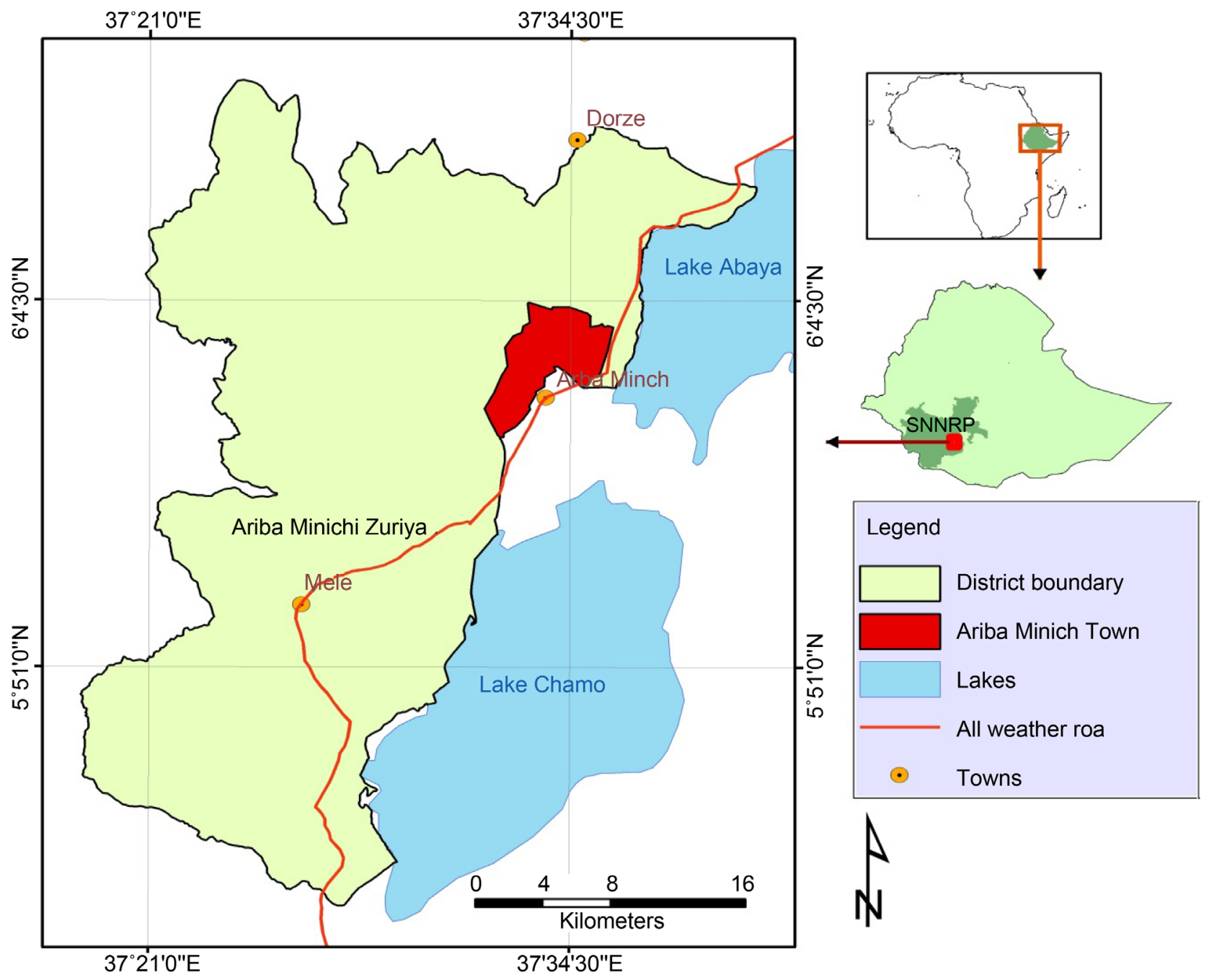

Figure 4. Location map of Arba Minch Zuriya District [11]. 
and the rest 10 are found in the low land zone. The district has a total area of 168,172 hectares of land with a total population of 74,879 in Arba Minch city and 164,529 in Arba Minch Zuriya district. The altitude of the district ranges from 1200 - 3300 masl with arainfall of $800 \mathrm{~mm}-1200 \mathrm{~mm}$ per annum. The temperature also ranges from $16^{\circ} \mathrm{C}-37^{\circ} \mathrm{C}$. There are two cropping seasons, namely, Belg (short rainy season), Meher (main rainy season). The short rainy season starts from March to May while the main rainy season is from Jun to September. The district is also surrounded by the two Rift Valley lakes namely Chamo and Abaya that have a great economic as well as ecological value to the area [12].

\subsection{Data Collection and Analysis}

For the realization of the research primary data was collected by making use of focus group discussions, semi structured interviews and review of related reports and literature. The participants (local community members) were selected by systematic sampling from the kebeles of the district. Government officials were also interviewed. A total of 58 ( 13 female) households and 5 officials participated for the data collection exercise. The primary information collected through focus group discussion, interview and observation was separately transcribed which helped the raw data to be ready for scientific analysis. Then content analysis of the information was made and main points were analyzed [13] [14].

\section{Results and Discussion}

Modern banana production in the district dates back to the early 1980s. Dwarf Cavendish and Medium Ambo are the major varieties produced in the area. The production system ranges from the backyard to the large scale farms owned by individuals and investors. Irrigation water from the rivers and streams and rainfall are the sources of water for the production of the crop (Figure 5).

Yishak [15] mentioned as the average irrigated land holding per $\mathrm{HH}$ varies from 0.15 ha to 1.32 ha of land. According to the focus group discussants most irrigation beneficiaries have the tendency of using their irrigation water resources for the production of banana, which is mainly an attribute of the economic importance of the crop as compared to Mango, Avocado and Papaya (Figure 6).

River diversion is the major source of irrigation water for banana production in the area. According to the respondents, the amount of water during the dry season will be reduced significantly and they will be forced to use the water in a very economical way. It was also observed as significant amount of water is being wasted in the farms since most of the farmers are making use of flooding as their way of irrigating their fields (Figure 7). This indicates as agricultural extension works need to focus on capacitating the farmers in irrigation agronomy so as to enhance the production in an environment friendly way. As a result of the improper use of irrigation water in many farm fields, water logging is mentioned as a hazardous challenge posed to the environment. In addition to this, the water logged areas are being breeding ground for mosquitoes which will affect the health and wellbeing of the productive agricultural human capital of the area. 

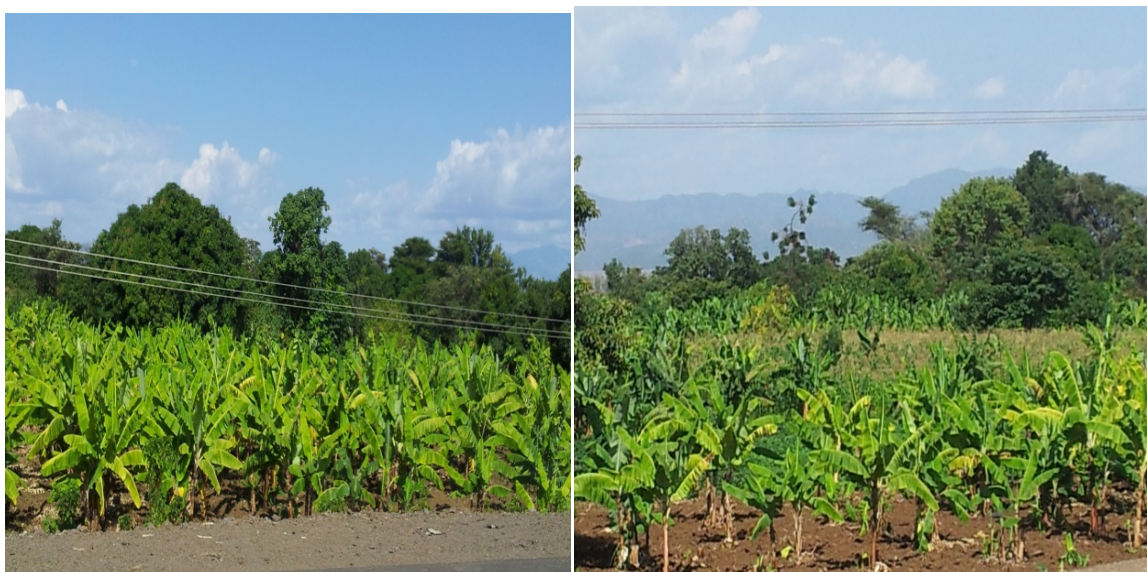

Figure 5. Banana production farms (Lante Kebele).

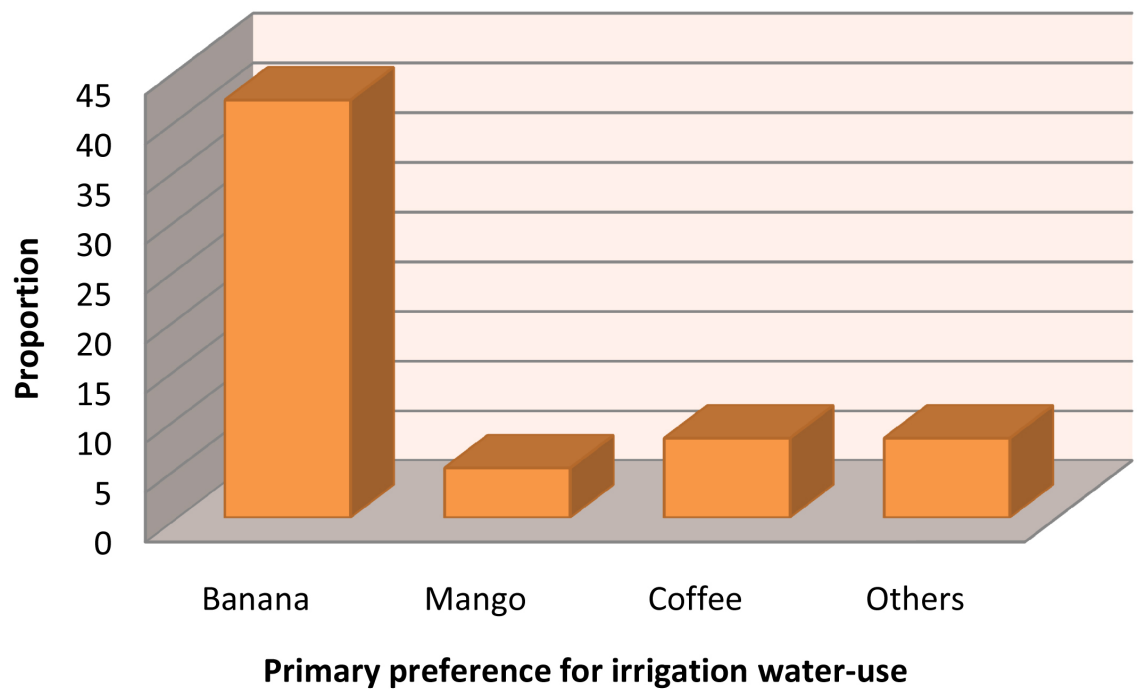

Figure 6. Respondents preference on irrigation water use for the different crops.

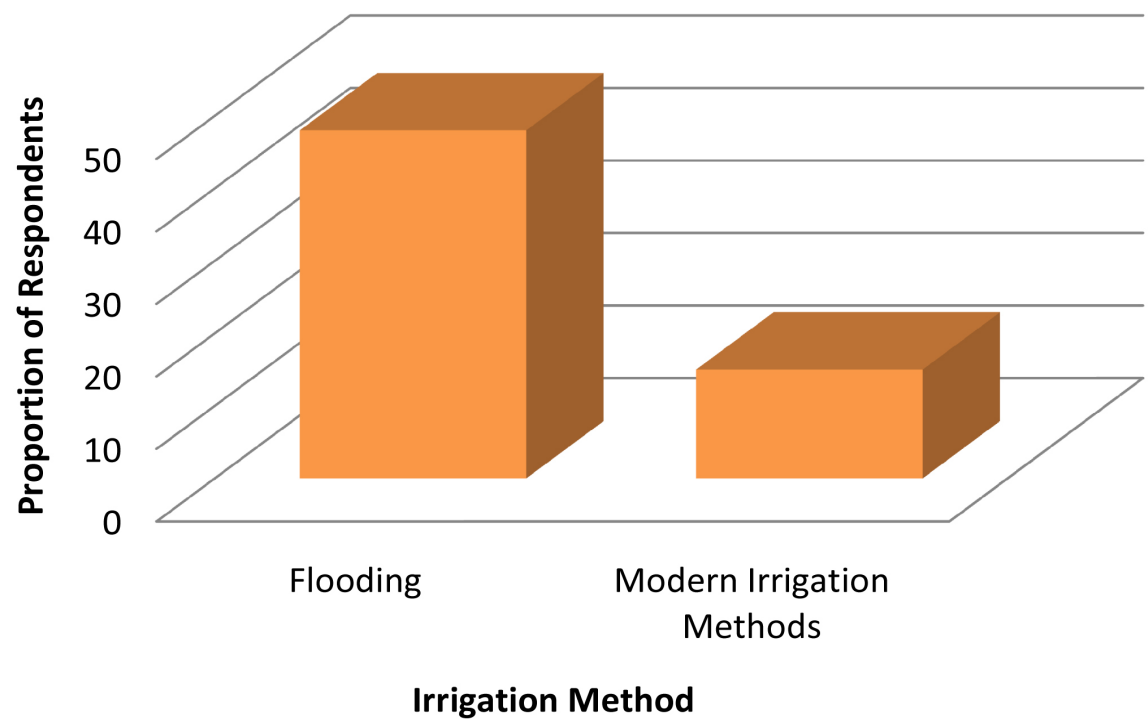

Figure 7. Respondents response on the type of irrigation methods used for banana production. 
The produce of the banana plantations is usually destined to the major cities of the country, Addis Ababa being the primary consumer which is located about $510 \mathrm{~km} \cdot \mathrm{s}$ from the production site. The produce is also destined to far distance cities such as Mekelle which is located about $1300 \mathrm{~km} \cdot \mathrm{s}$ from the source. Nazareth, Gondar, Bahir Dar and Dire Dawa are also among the major cities which they got their banana supply from the zone.

These market routes are largely controlled by wholesalers who operate in poorly designed market system, storage and transport facilities. This situation is not helping the producers who have exerted their major human and natural capital in the whole value chain of the crop. The producers will usually get a small amount of profit as compared to the value of the banana in the major cities (Table 1 and Table 2). While there is no question about the transformational development on the lives of the banana producers, they would have still enjoyed better life if the market information and the value chain of the crop were controlled in a harmonious way so that the profit margins between the producers and the major city wholesalers could be equitable.

In spite of the low profit margins, however, many of the respondent farmers confirmed as banana is their number one cash crop which is contributing a lot for the household food security, income generation and creation of employment

Table 1. Average price of banana in the major cities of the country.

\begin{tabular}{ccc}
\hline S.N & Destination Cities & Average Price $/ \mathrm{Kg} / \mathrm{Birr}^{*}$ \\
\hline 1 & Arba Minch (the production center) & 4.5 \\
2 & Addis Ababa & 17 \\
3 & Nazareth & 15 \\
4 & Mekelle & 16 \\
5 & Bahir Dar & 16 \\
\hline
\end{tabular}

*Average market prices of July, 2016 obtained from the retailers (the exchange rate of $\$ 1$ was equivalent to 21.87 Ethiopian Birr on July 28, 2016).

Table 2. Average price banana in the district per killo for the last 12 years [16].

\begin{tabular}{ccc}
\hline S.N & Year & Average Price/kg (Birr) \\
\hline 1 & 2005 & 1.2 \\
2 & 2006 & 1.1 \\
3 & 2007 & 1.35 \\
4 & 2008 & 1.25 \\
5 & 2009 & 2.15 \\
6 & 2010 & 4 \\
7 & 2011 & 4 \\
8 & 2012 & 3.9 \\
9 & 2013 & 4.4 \\
10 & 2014 & 4.8 \\
11 & 2015 & 5.1 \\
12 & 2016 & 4.5 \\
\hline
\end{tabular}


opportunities for the youth. The respondents have mentioned as they are able to maintain 3 meals per day which otherwise would have been impossible without the income generated from the banana production. According to the respondents banana production has also contributed for the enhancement of children school enrollment since the parents are able to afford school related expenses in a satisfactory way. The plantations are also serving as source of feed for the household level animal production activities.

As a result of improper irrigation practices, the banana production in the district is, however, being constrained by shortage of irrigation water especially during the summer season. This challenge can be minimized if intensive capacity development for farmers and water management systems are placed by the concerned government entities. The weak link between research and the production system also contributed a challenge for enhancing the productivity of the crop in the available land resources. Crop variety suitability and soil analysis could have also helped for a better recommendation of appropriate varieties to be produced in the area. Apart from this, raw bananas are directly harvested from the farm and will be piled up on each other at the back of the Isuzu tracks without having proper post-harvest handling facilities like boxes which could have helped in lowering down the post-harvest losses of the produce as a result of physical damage and poor ventilation related loses while travelling all the way from Arba Minch to the different destination cities (Figure 8).

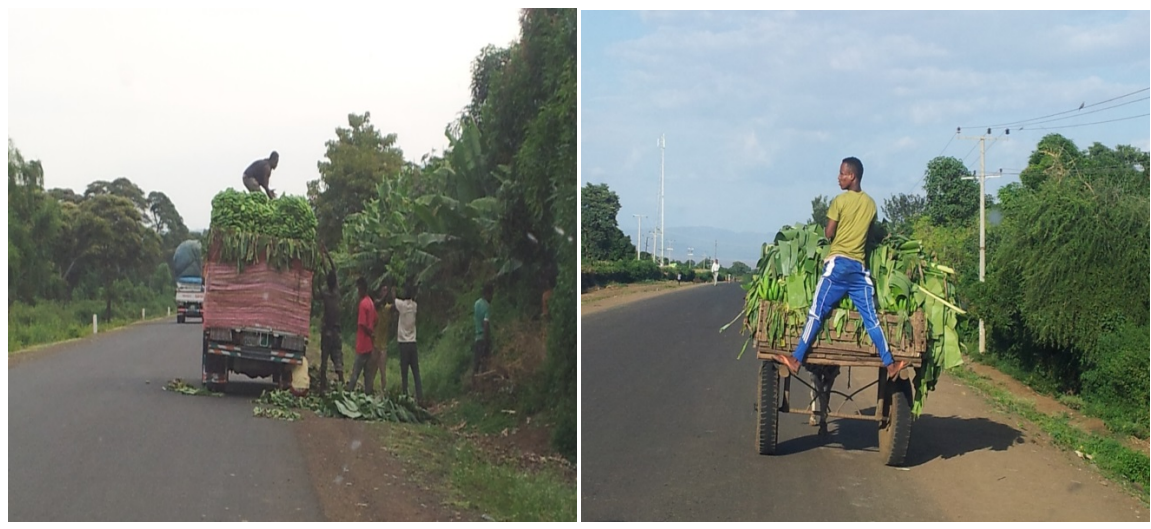

Figure 8. Bananas from farm fields to the different destinations.

\section{Conclusion}

Banana production has a significant contribution for the economic transformation of many households in the region. Its contribution to food security, income generation, employment opportunities and economic development is very magnificent. However, it is also a sad fact that many of the primary producers, namely farmers are not still making the advantage of production related transformations as a result of low savings culture of the local producers and weak market linkages and systems in the value chains of the crop. As a result, the wholesale traders are the one benefiting more than the producers. Apart from that, improper agronomic practices such as poor post-harvest handling practices, improper irrigation 
systems, poor land management practices and the mono-cropping nature of the banana production system will have a negative impact on the natural capitals of the area. Therefore, in order to attain equitable and sustainable development of the banana production, market information system, improved agronomic and irrigation systems and establishment and strengthening of new and existing cooperatives have to be considered by policy and decision makers if the banana production system of the area has to continue in a sustainable way by transforming the lives of the wider banana producers in an environment friendly way.

\section{References}

[1] Crane, J.H. and Balerdi, C.F. (2005) Banana Growing in the Florida Home Landscape. Institute of Food and Agricultural Science, HS 10.

[2] Bezuneh, T. (1975) Status of Banana Production in Ethiopia. ISHS Acta Horticulturae, 49, 271-274. https://doi.org/10.17660/ActaHortic.1975.49.34

[3] Woldu, Z., Mohammed, A., Belew, D., Shumeta, Z. and Bekele, A. (2015) Assessment of Banana Production and Marketing in Ethiopia. International Journal of Sciences: Basic and Applied Research, 24, 283-307.

[4] Dodo, M.K. (2014) Centre of Excellence Institute of European Studies. University of California, Berkeley and Centre de Documentaciò Europea Universitat de Valencia, USA.

[5] Dreamstime (2017) Banana Nutrition Facts.

https://www.dreamstime.com/stock-illustration-banana-nutrition-facts-clump-bana nas-label-nutrient-counts-image53596873

[6] FAO (Food and Agriculture Organization of the United Nations) (2015) Banana Market Review 2013-2014. Rome, Italy.

[7] Berhe, K., Puskur, R., Teka, W., Hoekstra, D. and Tegegne, A. (2008) Innovation in Banana Value Chain development in Metema District, Northwestern Ethiopia: IPMS Experiences Improving Productivity and Market Success (IPMS) Project. International Livestock Research, Addis Ababa, Ethiopia.

[8] CSA (Central Statistical Agency of Ethiopia) (2014) Agricultural Sample Survey. Report on Area and Production of Major Crops. Volume I, VII and VIII. Statistical Bulletin 578. Addis Ababa, Ethiopia.

[9] CFC (Common Fund for Commodities) (2004) Development of Organic Banana Production and Export in Sudan and Ethiopia to the Middle East and Europe. FC/CC/34/FISGB/10.Appraisal Report, Addis Ababa, Ethiopia.

[10] Mekonnen, F. (2014) The History and Future of Banana in Arba Minch, Ethiopia. Livestock and Irrigation Value Chains for Ethiopian Smallholders. https://lives-ethiopia.org/2014/02/25/banana-history/

[11] MoARD (Ministry of Agriculture and Rural Development) (2005) Woody Biomass Strategic Planning Project. A National Strategic Plan for Biomass Energy Sector, Addis Ababa, Ethiopia.

[12] FDRE-PCC (Federal Democratic Republic of Ethiopia, Population Census Commission) (2008) Summary and Statistical Report of the 2007 Population and Housing Census. Addis Ababa, Ethiopia.

[13] Hennie, B. (2010) Analysis in Qualitative Research. SAGE, Los Angeles.

[14] Flick, U., Kardorff, E. and Steinke, I. (2004) A Companion to Qualitative Research. Sage Publications, London. 
[15] Baredo, Y. (2013) Gamo Gofa Zone Diagnosis and Planning Document, SNNP. (Compiled by, LIVES Project Coordinator)

[16] Lante, O. (2016) Fruits \& Vegetables Marketing Primary Cooperatives, Banana Production. Lante, Araba Minch, Ethiopia.

\section{Scientific Research Publishing}

Submit or recommend next manuscript to SCIRP and we will provide best service for you:

Accepting pre-submission inquiries through Email, Facebook, LinkedIn, Twitter, etc. A wide selection of journals (inclusive of 9 subjects, more than 200 journals) Providing 24-hour high-quality service User-friendly online submission system Fair and swift peer-review system Efficient typesetting and proofreading procedure Display of the result of downloads and visits, as well as the number of cited articles Maximum dissemination of your research work

Submit your manuscript at: http://papersubmission.scirp.org/

Or contact jep@scirp.org 